\title{
CAPACITANCE AND POWER FACTOR OF A MICA CAPAC- ITOR AS MEASURED AT THE BUREAU OF STANDARDS AND THE NATIONAL PHYSICAL LABORATORY
}

\author{
By Harvey L. Curtis, C. Matilda Sparks, L. Hartshorn, ${ }^{1}$ and N. F. Astbury ${ }^{1}$
}

\section{ABSTRACT}

A mica capacitor has been transported on four occasions between the Bureau of Standards and the National Physical Laboratory. Seven sets of measurements of capacitance and power factor were made on the capacitor, five at the Bureau of Standards and two at the National Physical Laboratory. During the first transportation changes occurred in the capacitance, which make the results of little value. No certain changes occurred during subsequent transportations.

The principles underlying the methods of the two laboratories are quite different At the Bureau of Standara's the mica capacitor was compared by alternating current with an air capacitor, the capacitance of which can be determined in terms of resistance and time. At the National Physical Laboratory the mica capacitor was compared by alteranting current with a mutual inductance, the value of which can be computed from its dimensions. Results show that the two methods give values in good agreement. The measured capacitances agree to 1 or 2 parts in 10,000 , which is about the accuracy of the measurements.

\section{CONTENTS}

I. Introduction .

II. The capacitor

III. Times of shipping and measuring the capacitor

IV. Conditions under which measurements were made._.

V. Methods of testing at the Bureau of Standards

1. Air capacitor 509

2. Alternating current bridge..... 509

3. Absolute capacitance bridge. 511

VI. Methods of test at the National Physical Laboratory

1. Primary standard of mutual inductance. 512

2. Working standard of mutual inductance 513

3. Carey Foster biidge for measurements of capacitance and

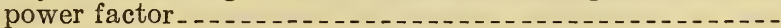

VII. Results

VIII. Conclusions

\section{INTRODUCTION}

In November, 1927, an agreement was reached to undertake some intercomparisons of the capacitance and power factor of a mica capacitor. A subdivided mica capacitor selected for this comparison was calibrated alternately at the Bureau of Standards and the National Physical Laboratory by the methods regularly used in the two laboratories. This comparison has extended over a period of more than three years. The capacitor was first carried from Washington to Teddington by a special messenger. The three subsequent transits were made by parcel-post shipment.

The results show that the values of the international microfarad as maintained at the two laboratories are the same within the limits of the present intercomparison.

1 National Physical Laboratory, Teddington, England.

$$
105570-32-5
$$




\section{THE CAPACITOR}

The mica capacitor chosen for intercomparison was a subdivided one purchased by the Bureau of Standards about 1917 and designated as B. S. 16390. It consists of eight sections, the sections being designated according to their capacitances as $0.01,0.02,0.02^{\prime}, 0.05$, $0.1,0.1^{\prime}, 0.2$, and 0.5 The sum of the three smallest sections connected in parallel is designated as $\Sigma 0.05$, of the four smaller sections as $\Sigma 0.1$, and the sum of all eight sections as $\Sigma 1.0$. From the time of acquisition until these comparisons were undertaken this capacitor had been subjected to ordinary laboratory service at normal room temperatures. Occasional calibrations during this period showed that both the capacitance and power factor were approximately constant. It, therefore, seemed well suited for the intercomparison. Each section of the capacitor is constructed from sheet mica interleaved with tinfoil, the completed section being impregnated with paraffin and clamped between brass plates about $4 \mathrm{~mm}$ thick. The distance between individual sections is about $2 \mathrm{~cm}$. The two terminals of each section are brought out to individual binding posts mounted on a hard-rubber top. The clamping plates are not connected to either terminal. There is no shield to the individual sections nor to the capacitor as a whole, the container being a wooden box.

\section{TIMES OF SHIPPING AND MEASURING THE CAPACITOR}

The capacitor was measured at the Bureau of Standards in April, 1928. In July, 1928, it was sent to the National Physical Laboratory, where measurements were made in January, 1929. It was returned to the Bureau of Standards in the spring of 1929 , where it was measured in June, 1929, and again in January and February, 1930. In May, 1930, it was again sent to the National Physical Laboratory, where measurements were made in September of that year. It was returned to the Bureau of Standards in the fall of 1930, a set of measurements made in March 1931, and the final set of the series made in February, 1932.

\section{CONDITIONS UNDER WHICH MEASUREMENTS WERE MADE}

At both laboratories the temperature of the capacitor was maintained during measurement at $25^{\circ} \mathrm{C} . \pm 0.1^{\circ} \mathrm{C}$. The first measurements at each laboratory were made at four frequencies, namely, $60,100,1,000$, and 2,000 cycles per second; subsequent measurements were made at 60 and 1,000 cycles only. In all cases the air pressure was the barometric pressure at the laboratory. It is improbable that the differences in the barometric pressure caused either by the relative altitudes of the two laboratories or by the ordinary variations will produce a change in capacitance greater than 1 part in $10,000 .^{2}$

2 The pressure variation caused by the difference in altitude is about $1 \mathrm{~cm}$ of $\mathrm{Hg}$. The maximum variation at any one place is about $5 \mathrm{~cm}$ of $\mathrm{Hg}$. A mica capacitor usually changes about 0.2 parts in 10,000 per
centimeter change in pressure. See Bul. $\mathrm{B}$. 


\section{METHOD OF TESTING AT THE BUREAU OF STANDARDS}

The method of testing a capacitor of unknown value at the Bureau of Standards is to compare it, either directly or indirectly, with an air capacitor, the value of which has been determined in terms of resistance and time. The comparison between the unknown and the air capacitor is made with alternating current of the desired frequency, the assumption being made that the capacitance of the air capacitor is independent of the method of measurement and that its power factor is zero.

\section{AIR CAPACITOR}

The bureau possesses a bank of fixed air capacitors so arranged that any capacitance between $0.01 \mu \mathrm{f}$ and $0.26 \mu \mathrm{f}$ can be obtained in the $0.5 \mu$ fection of the unknown with the five $0.1 \mu \mathrm{f}$ capacitors connectsteps of $0.01 \mu \mathrm{f}$. Hence seven sections of the mica capacitor were compared directly with air capacitors of the same nominal values, while only in the case of the $0.5 \mu \mathrm{f}$ section and the sum of all the sections was an indirect comparison necessary. The most satisfactory scheme for obtaining values of the $0.5 \mu \mathrm{f}$ section was to compare the capacitance and power factor of each of five $0.1 \mu \mathrm{f}$ standard mica capacitors with an air capacitor of the same value; then to compare ed in parallel. To obtain a standard of $1.0 \mu \mathrm{f}$ with which to compare all the sections of the unknown connected in parallel, two standard mica capacitors each having a nominal value of $0.5 \mu \mathrm{f}$ were first compared with the five $0.1 \mu \mathrm{f} \mathrm{mica}$ capacitors connected in parallel, then these two $0.5 \mu$ f capacitors were used in parallel to give the required $1.0 \mu \mathrm{f}$ standard.

The accuracy which can be attained by the indirect comparison with an air capacitor as described above can be judged by the values for the $\Sigma$ sections as given in Table 4 . For the $\Sigma 0.05$ and $\Sigma 0.1 \mu \mathrm{f}$ sections, the measured value of each was obtained by direct comparison with an air capacitor, while the computed value was obtained by the summation of the measured values of the individual sections. The measured value of the $\Sigma 1.0 \mu$ f section was obtained by the method as described using mica standard capacitors, whereas the computed values of the same $\Sigma$ section were obtained by summing the values of the separate sections as independently obtained. This method is less satisfactory for small values of capacitance than for large values, since the greatest source of error is caused by the capacitance of the leads; the smaller the capacitance of the section, the greater the percentage of error. For the $\Sigma 1.0 \mu \mathrm{f}$ section the maximum difference between the measured and the computed values of the capacitance is 2 parts in 10,000, while for the power factor the maximum difference is $1 \times 10^{-4}$. For the $\Sigma 0.1 \mu \mathrm{f}$ section the differences between the measured and computed values are approximately the same as for the $\Sigma 1.0 \mu$ f section, while for the $\Sigma 0.05 \mu$ f section they are somewhat larger.

\section{ALTERNATING-CURRENT BRIDGE}

The method used for the comparison of capacitance is the seriesinductance bridge of Rosa. ${ }^{3}$ For comparisons at 60 and 100 cycles per second a vibration galvanometer was used as the detecting instru-

This bridge was first described by Grover, Bul. B. S. vol. 3, p. 389, 1907. The form now used in thes laboratory is described by Curtis, Bul. B. S. vol. 6, p. 435, 1911. 
ment. For frequencies of 1,000 and 2,000 cycles per second a telephone receiver was used for the detector. In measuring capacitances of $0.2 \mu \mathrm{f}$ and smaller a bridge of three branches was used, one of which had a ground ${ }^{4}$ connection at the galvanometer terminal. A substitution method was employed in all measurements. A diagram of the bridge is given in figure 1. One terminal of the detector, $G$, is permanently connected to point, $A$, on the first branch of the bridge. The second terminal, by means of the double-throw switch, can be

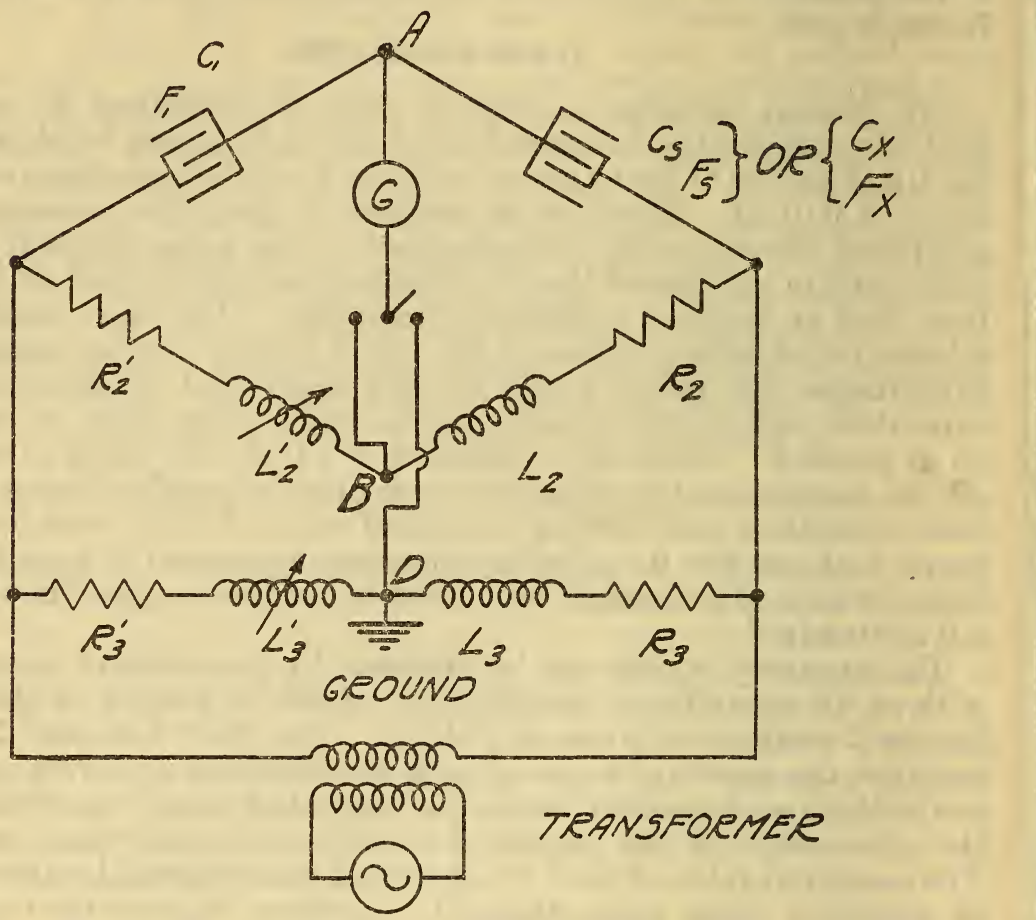

Figure 1.-Diagram of a. c. bridge used at the Bureau of Standards for comparing capacitors

$C_{1}$, auxiliary capacitor having capacitance $C_{1}$ and power factor $F_{1}$.

$C_{s}$, standard capacitor having capacitance $C_{\varepsilon}$ and power factor $F_{s}$.

$C_{x}$, test capacitor having capacitance $C_{x}$ and power factor $F_{x}$.

$G$, detector.

$R$ and $L$ )with subscript and superscript), total resistance and total inductance, respectively, of the designated arms.

connected to either points $B$ or $D$ of the second and third branches, respectively. With the standard capacitor $C_{s}$ in the bridge and an auxiliary capacitor $C_{1}$ having the same nominal value of the capacitance, the resistance of $R_{2}^{\prime}$ (including the resistance of the inductor $L_{2}^{\prime}$ ) is made numerically equal to some decimal multiple of the value of $C_{s}$. The detector is connected to $B$ and a balance obtained by adjusting the resistance $R_{2}$ and the inductor $L^{\prime}{ }_{2}$. The detector is then connected to $D$ and $R^{\prime}{ }_{3}$ and $L^{\prime}{ }_{3}$ adjusted for a balance. The detector is again connected to $B$ and, if necessary, a new adjustment made for a balance. This shifting from one arm to the other with

1 This is a method proposed by K. W. Wagner, Elekt. Zeit. vol. 32, p. 1001, 1911. 
consequent balancing is continued until changing the connection does not require a change in balance. Then, provided the ratios $L_{2} / R_{2}$ and $L_{2}^{\prime} / R_{2}^{\prime}$ are both small, the equation connecting capacitances and resistances is

$$
C_{1} / R_{2}=C_{s} / R^{\prime}{ }_{2}
$$

and the equation for computing the power factor is

$$
F_{s}-F_{1}=\omega\left(L_{2} / R_{2}-L^{\prime}{ }_{2} / R^{\prime}{ }_{2}\right)
$$

Now the standard capacitor $C_{s}$ is replaced by the unknown capacitor $C_{x}$. The bridge is now balanced by adjusting $R^{\prime}{ }_{2}$ (not $R_{2}$ as when the standard is in the bridge) and $L^{\prime}{ }_{2}$ to have the values $R^{\prime \prime}{ }_{2}$ and $L^{\prime \prime}{ }_{2}$, and by adjusting $R^{\prime}{ }_{3}$ and $L^{\prime}{ }_{3}$, using the same method as for the standard. Now

$$
\frac{C_{1}}{R_{2}}=\frac{C_{x}}{R^{\prime \prime}{ }_{2}}
$$

and

$$
F_{x}-F_{1}=\omega\left(\frac{L_{2}}{R_{2}}-\frac{L^{\prime \prime}{ }_{2}}{R^{\prime \prime}{ }_{2}}\right)
$$

Combining these with the equations when the standard is in the bridge

$$
C_{x}=R^{\prime \prime}{ }_{2} \frac{C_{s}}{R^{\prime}{ }_{2}}
$$

and

$$
F_{x}-F_{s}=\omega\left(\frac{L^{\prime}{ }_{2}}{R_{2}{ }_{2}}-\frac{L^{\prime \prime}{ }_{2}}{R^{\prime \prime}{ }_{2}}\right)
$$

Since $R_{2}^{\prime}$ was made a decimal multiple of $C_{s}$, the equation shows that $C_{x}$ is the same decimal multiple of $R^{\prime \prime}{ }_{2}$, thus simplifying the computation. When $C_{s}$ is an air capacitor, $F_{s}$ is assumed to be zero.

The substitution method does not require an accurate knowledge of the values of the resistances, since only the ratio $R^{\prime}{ }_{2} / R^{\prime \prime}{ }_{2}$ enters in the final computation. If in the change of the resistance from the value $R_{2}^{\prime}$ to $R^{\prime \prime}{ }_{2}$ only coils of small value are inserted or removed, a calibration of the resistances to a high relative accuracy is not necessary to give a precise value of the ratio of the two capacitances.

\section{ABSOLUTE CAPACITANCE BRIDGE}

To obtain the capacitance values of the air capacitors, measurements are made in terms of resistance and time by Maxwell's method. ${ }^{5}$ In this method a ballistic galvanometer is used to compare a constant current flowing in one direction through the galvanometer with the integral value of a current in the opposite direction produced by the series of charging currents when a capacitor is charged and discharged at a rapid rate. The assumption is made that the standard air capacitors of the Bureau of Standards have the same capacitance under all methods of measurement herein employed, this being sup-

${ }^{5}$ For details of using the method at the bureau, see paper by Curtis and Moon, B. S. Sci. Papers, vol. 22, p. $487,1927$. 
ported by the fact that they have the same capacitance when measured with 100 charges and discharges per second as with 1,000 charges and discharges per second.

It is possible to obtain by this method results accurate to a few parts in a hundred thousand. However, to obtain that accuracy, great care must be exercised in the calibration of the resistance arms of the bridge and in the measurement of the number of charges and discharges per second of the capacitor. The highest order of accuracy was not attempted in the measurements herein reported. There is a possibility of an error of 1 or 2 parts in 10,000 from uncertainty in the values of the resistances and a somewhat smaller error from the time measurements.

\section{METHODS OF TEST AT THE NATIONAL PHYSICAL LABORATORY}

At the National Physical Laboratory, measurements of capacitance are made by a direct comparison with the standards of mutual inductance and resistance. The value of the primary standard of mutual inductance is obtained in centimeters by calculation from its dimensions, and the determination of capacitance is thus an absolute measurement, since the values of the resistance standards are also known in c. g. s. units. The values of capacitance are, therefore, obtained in absolute microfarads. For practical purposes it is important that the unit of capacitance shall be consistent with the unit of resistance and since it is known that

$$
1 \text { international } \mathrm{ohm}=1.0005 \mathrm{ohms} \text { (c. g. s.) }
$$

the results of the capacitance measurements are converted to international units by the use of the relation

$1 \mu \mathrm{f}$ (absolute or c. g. s.) $=1.0005$ international microfarad

\section{PRIMARY STANDARD OF MUTUAL INDUCTANCE}

The primary standard mutual inductor of the National Physical Laboratory has been described in previous papers. ${ }^{6}$ For the present purpose it is sufficient to state that the primary coil consists of a single layer solenoid wound in two sections on a marble cylinder; the secondary coil is larger in diameter than the primary and contains many more turns (about 500). This design was adopted as giving an inductance of convenient value for most purposes $(10 \mathrm{mH})$, in a form which is as permanent as possible, and on which it is possible to obtain the highest accuracy in the determination of the linear dimensions, and the calculation from them of the mutual inductance. This calculated value of the mutual inductance is only realized in practice when the frequency of the alternating current supplied to the instrument is so low that the effects of capacitance in and between the windings are negligibly small. It will, however, be evident that the effects of capacitance will be comparatively large in a standard of this form, owing to the large size of the secondary coil, and it is, therefore, impossible to use the primary standard itself in precision work at

${ }^{6}$ A. Campbell, N. P. L. Collected Researches, vol. 4, p. 213; or Proc. Roy. Soc. A., vol. 79, p. 428, 1907; also Proc. Roy. Soc. A. vol., 87, p. 391, 1912. 
telephonic frequencies. Secondary standards, designed to have smaller capacitance effects, and also to be continuously variable and direct reading are, therefore, used for alternating current bridge work. These are calibrated in terms of the primary standard at a frequency of 10 cycles per second, at which frequency the capacitance effects on the primary standard are known to be of the order of 1 part in $1,000,000$.

\section{WORKING STANDARDS OF MUTUAL INDUCTANCE}

The mutual inductors used in alternating current bridge work at the National Physical Laboratory take the form of the Campbell inductometer. ${ }^{7}$ The instrument used for this work covered the range 0 to $11 \mathrm{mH}$, so that the reading $10 \mathrm{mH}$ could be measured against the primary standard by a simple direct comparison at the frequency of 10 cycles. The range of the instrument is subdivided into hundredths by means of two successive decade dials, and further subdivision is obtained by including in the secondary winding a small moving coil, carrying a pointer which moves over a scale graduated in microhenries of mutual inductance. The instrument could be read to the nearest $0.1 \mu \mathrm{H}$ at any point of its range; that is, to an accuracy of 1 part in 100,000 of the total value. The accuracy of subdivision is checked as follows: By the fitting of a special switch to the decade dials, the various tenths into which each dial is divided are compared with one another, and thus each is determined in terms of their sum. The comparison of the various tenths is made by simple substitution in a circuit which allows any one of them to be balanced against a fixed mutual inductance of about the same value, the small moving: coil of the instrument being used to take up the differences. The same process is applied to the second decade dial. The scale of the moving coil is calibrated by the use of Albert Campbell's device of the 10-strand cable; that is, an auxiliary mutual inductance adjustable in value is obtained by means of two coils, one of which is wound with a cable of 10 strands well twisted together. The 10 strands are connected in series, and the junctions are brought to the studs of a decade dial, so that between studs $O$ and $n$ there are $n$ strands in series. The dial having been set at stud 10 , the value of the mutual inductance is adjusted by moving one of the coils bodily until the total mutual inductance exactly balances the mutual inductance which is to be subdivided. Tenths of this value are than obtained by taking the intermediate settings of the dial. The accuracy of the subdivision may be increased as required by arranging the coils to be farther apart. All the readings required in the calibration are taken on the scale of the small moving coil of the inductometer, which is always included in the circuit.

It will be observed that all the calibrations depend on the principle that mutual inductances between several secondary coils and a common primary are additive. The principle assumes that capacitance effects are negligible, and care is taken to ensure that this is so, by the use of low frequency (100 cycles or less) for all such calibrations.

When the above-mentioned calibrations have been carried out, the value of the low-frequency or geometrical mutual inductance of the instrument is known for every reading, but when the instrument is

\footnotetext{
7 A. Campbell, Proc. Phys. Soc., vol. 21, p. 69, 1908.
} 
used at frequencies greater than 100 cycles, allowance must be made for the effects of capacitance and eddy currents in the windings. As a result of these effects, the secondary voltage $V_{s}$ of the instrument is not exactly in quadrature with the primary current $I_{p}$, and is not simply proportional to the frequency and the value of the geometrical inductance $M_{o}$. Instead of the simple ideal equation $V_{s}=j \omega M_{o}$, we must write

$$
\begin{aligned}
V_{s} & =\left[\sigma+j\left(M_{0}+\Delta M\right) \omega\right] I_{p} \\
& =[\sigma+j M \omega] I_{p}
\end{aligned}
$$

where $\sigma$ and $\Delta M$ are correcting terms representing the effects of capacitance and eddy currents. These are called for convenience the "impurity" and "frequency correction," respectively, of the instrument at the reading $M_{0}$ and the frequency $\omega / 2 \pi$. The quantity $M_{0}+\Delta M=M$ is called the "effective mutual inductance" of the instrument and the small angle $\tan ^{-1} \frac{\sigma}{M \omega}$ is called, for obvious reasons, its "phase defect."

The values of the phase defect and frequency correction of the secondary standard inductors are determined by comparing them at several frequencies covering the working range, with mutual inductors wound of highly stranded wire in such a manner that capacitance and eddy currents effects are reduced to a minimum. Their design is identical with that used for standard inductors for radio-frequency work, and the effects of capacitance in them are actually deduced from measurements of their self-capacitance at radio-frequencies. ${ }^{8}$

Two other properties of the secondary standard inductors are of importance for capacitance measurement; the self-inductance and resistance of the fixed or nonadjustable winding. The geometrical or low-frequency value of this self-inductance, $L_{o}$, is measured in terms of the mutual inductance by means of the Heaviside bridge in the form developed by Albert Campbell. ${ }^{9}$ The low-frequency value of the resistance $p$ is determined by a simple direct-current measurement. When the working frequency exceeds 100 cycles, these quantities also must be corrected for the effects of capacitance and eddy currents in the windings which manifest themselves as an increase in the effective values of the inductance and resistance. The effective self-inductance becomes $L_{0}+\Delta L$, and the effective resistance $p+\Delta p$. The small correcting terms $\Delta L$ and $\Delta p$ are determined by a comparison of the coil, at the required frequencies, with a standard inductor of the type used as standards in radio-frequency work. The effects of capacitance and eddy currents are reduced to a minimum in such standards, and may be estimated with sufficient accuracy from the results of measurements of self-capacitance and effective resistance at radio frequencies.

\section{CAREY FOSTER BRIDGE FOR MEASUREMENTS OF CAPACITANCE AND POWER FACTOR}

The actual measurement of capacitance in terms of mutual inductance and resistance is made by means of the Carey Foster bridge, in a form adapted to the requirements of precision alternating-current

8 L. Hartshorn, Proc. Phys. Soc., vol. 38, p. 307, 1926.

A. Campbell, Proc. Phys. Soc., vol. 21, p. 69, 1908. 
work. A complete account of the method as used at the present time has not hitherto been published, but notes on certain of the essential features have been given by A. Campbell, ${ }^{10} \mathrm{~S}$. Butterworth, ${ }^{11}$ and D. Dye. ${ }^{12}$

The circuit now used is shown in Figures 2 and 3, of which Figure 2 shows the electrical network in its simplest form, and Figure 3 gives the actual arrangement of the apparatus used. The bridge proper consists of the network $F A B D$, which is supplied with alternating current from the triode oscillator $O$. The detector of balance $G$ is a telephone receiver or Campbell vibration galvanometer, depending on the frequency at which the measurements are to be made. $M$ is the standard variable mutual inductor described above, of which $F A$

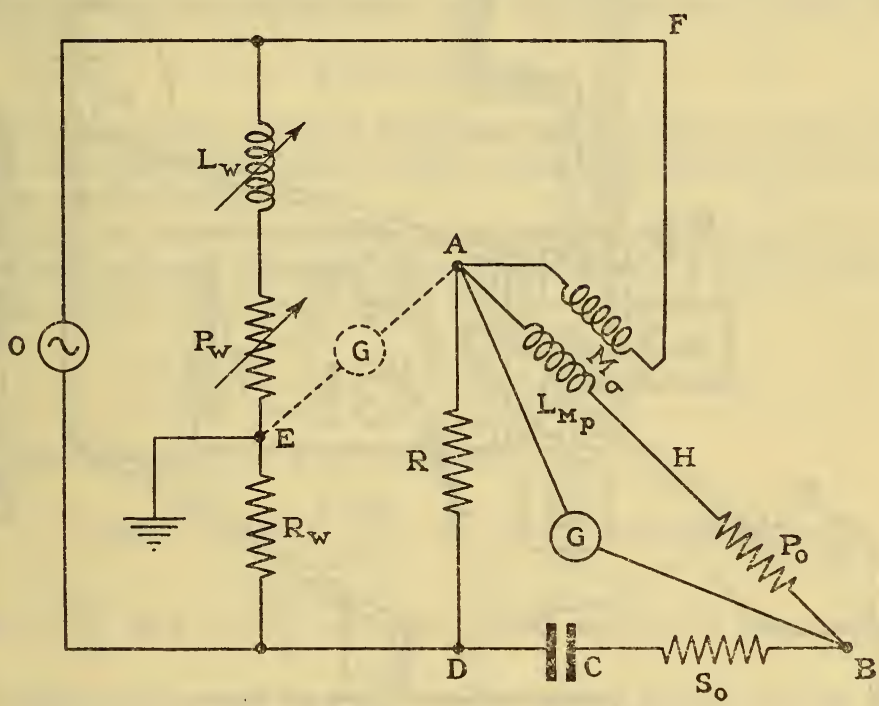

Figure 2.-Carey Foster bridge for the measurement of capacitance and power factor; simplified circuit diagram

$C$, capacitor under test.

$M$, standard variable mutual inductor.

$P_{0}, R$, fixed resistors.

So, variable resistor.

$L_{*}, P_{*}, E, R_{*}$, Wagner earth connection.

is the adjustable winding, and $A H$ the fixed winding. $P_{o}, R$, and $S_{o}$ are nonreactive resistors which take the following forms. $P_{0}$ and $R$ are fixed resistance coils of various sizes, oil-immersed, and electrostatically shielded by brass containers. $S_{o}$ is a nonreactive resistance box capable of fine adjustment, and inclosed in a metal shield which is connected to one of its terminals, as shown in Figure 3. $C$ is the condenser under test. It is inclosed in an earth-connected metal inclosure, and is connected to the bridge by means of leads which are also shielded, as shown in Figure 3. It will be observed that the oscillator $O$ and detector $G$ are connected to the bridge through two reversing switches $Z$, and $Y$ by means of shielded twin cable, and that the bridge is provided with a Wagner earth connection $L_{w} P_{w}$ $E R_{w}$. This consists of a fixed resistor $R_{w}$ of the same order as $R$,

${ }^{10}$ A. Campbell, Proc. Phys. Soc., vol. 20, p. 626, 1907.

11 S. Butterworth, Proc. Phys. Soc., vol. 33, p. 313, 1921.

12 D. W. Dye, Electrician, vol. 87, p. 55, 1921 . 
a variable resistor $P_{w}$, and a variable self inductor $L_{w}$. The point $E$ is connected to earth, and by means of a small switch $X$, the telephone or galvanometer can be changed rapidly from position $A B$ to $A E$.

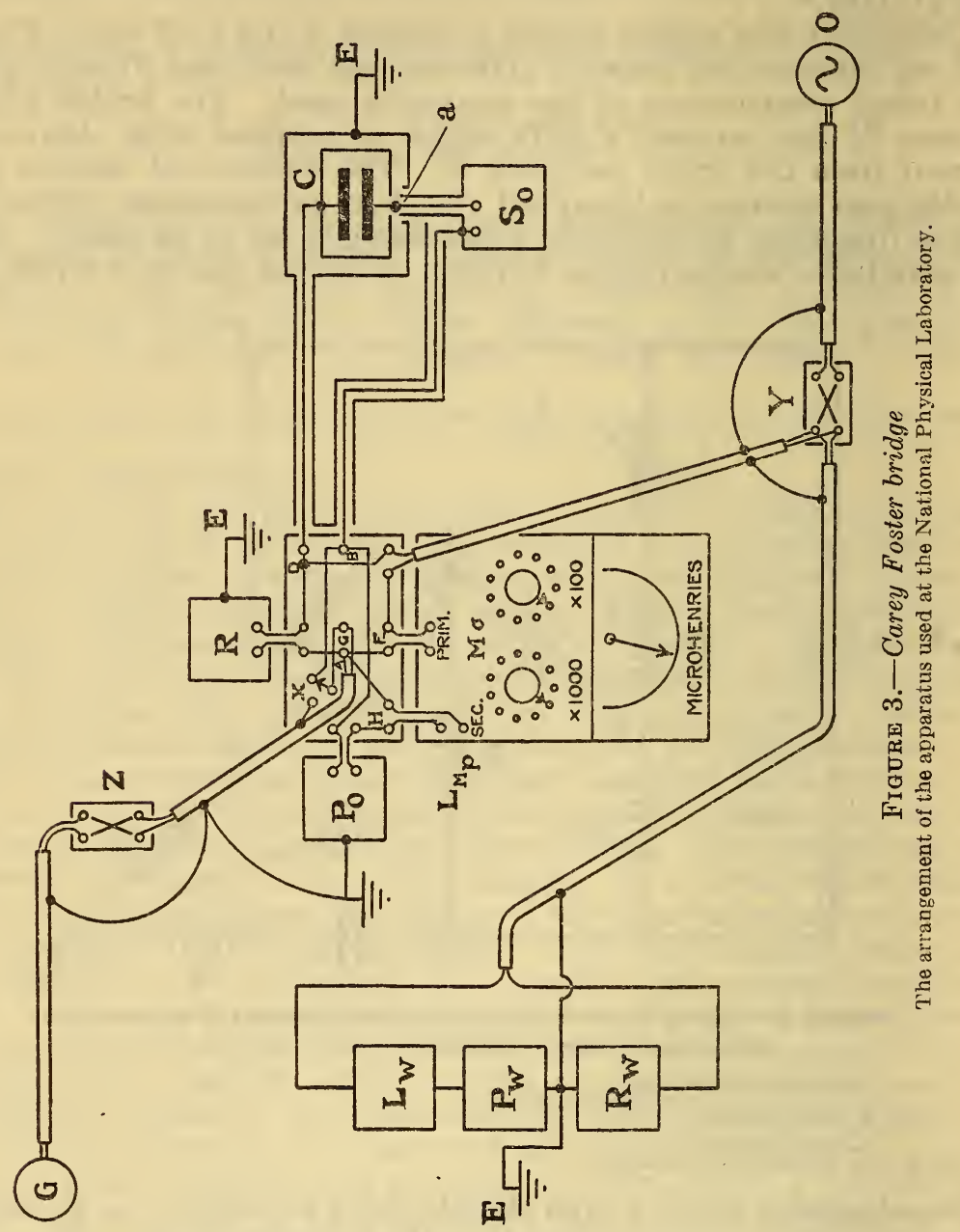

The equations of balance of the network $F A B D$ are

where

$$
\begin{gathered}
C=\frac{M}{P R}\left[1+\frac{\omega^{2} l_{R}(L-M)-l_{s} M \omega^{2}}{P R}+\frac{\sigma(R+S)}{P R}\right] \\
R+S_{o}+S_{c}=\frac{R L}{M}+P \frac{l_{R}}{M}+\frac{\sigma}{C M \omega^{2}}
\end{gathered}
$$

$C$ is the total capacitance of the arm $D B$, including the condenser and the residual capacitance of the shielded connecting leads.

$S$ is the total effective resistance of the arm $D B$, including that of the resistor and connecting leads $S_{o}$ and the effective series resistance of the condenser $S_{c}$.

$$
S=S_{o}+S_{c} \text {. }
$$


$M$ and $\sigma$ are the effective mutual inductance and impurity, respectively, between the arms $F A$ and $A B$, in practice the values for the standard inductor.

$L$ is the effective self-inductance of the arm $A B$, including the geometrical value of the fixed coil of the inductor $L_{o}$, the correction for capacitance and eddy current effects $\Delta L$, and the self-inductance of the resistor and connecting leads $l_{p}$.

$$
L=L_{o}+\Delta L+l_{p}
$$

$P$ is the effective resistance of the arm $A B$, including the value of the fixed resistor $P_{o}$, the d. c. resistance of the fixed coil of the inductor and the connecting leads, $p$, and the resistance correction for capacitance and eddy current effects in this coil $\Delta p$.

$$
P=P_{o}+p+\Delta p
$$

$l_{R}$ and $l_{S}$ are the residual self-inductance values of the resistors $R$ and $S_{o}$, including the leads connecting them to the junction box of the bridge.

The equations may be thrown into more convenient practical forms by the substitution of the approximate relation $M=C P R$ in the small correcting terms. We then obtain for the value of $C$

$$
C=\frac{M}{P R}\left[1+(R+S) C \omega \delta_{M}+S C \omega\left(\delta_{R}-\delta_{S}\right)\right]
$$

and for the loss angle $\delta$ of the condenser

$$
\tan \delta=S_{c} C \omega=\left[\frac{R L}{M}-\left(R+S_{o}\right)\right] C \omega+\delta_{R}+\delta_{M}
$$

where $\delta_{R}=\frac{l_{R} \omega}{R}$ and $\delta_{S}=\frac{l_{S \omega}}{S}$ are the phase angles of the resistors $R$ and $S$ respectively, and $\delta_{M}=\frac{\sigma}{M \omega}$ is the phase defect of the mutual inductor.

The main bridge is balanced by adjustments of $M$ and $S$. The Wagner auxiliary balance is made by adjustments of $L_{v}$ and $P_{v}$, and the various adjustments are made in succession until balance is obtained for both positions of the switch $X$. The effects of earth capacitance at the points $A, B, D$, and $F$ are then eliminated from the readings of the bridge proper. It will be noticed that with the arrangement of screens used, the capacitance of the leads to the condenser are in this way eliminated from the measurements, as are also the earth capacitance of the shield of the condenser (or the outer plates, if it is unshielded), and the shield of the resistance box $S_{0}$. It should be noticed also that all external screens are brought to earth potential. The earth capacitance of the lead connecting $S_{o}$ and $C$ is not eliminated from the measurements and is apt to cause an error when small condensers are under test, unless this lead is kept as short as possible, and shielded as shown in Figure 3.

The readings of $M$ and $S$ corresponding to the condition of balance are noted. The reversing switches $Y$ and $Z$ are operated in turn, the bridge being rebalanced after each reversal. The mean of the four readings corresponding to the four possible relative positions 
of these switches, is taken as the correct reading. The four readings differ by only a very slight amount, which represents the effect of stray inductances between oscillator, detector, and the various bridge components.

The temperatures of the coils $P$ and $R$ are noted so that their resistance values can be read from the calibration charts. The resistance $(p)$ of the fixed coil of the inductor, and also that of the resistance $S_{o}$ are then measured on a Wheatstone bridge with direct current.

The "zero" reading of the bridge is obtained as follows: The condenser is disconnected at the point $(a)$ and the bridge again balanced. The reading of the inductor for this balance is very nearly zero; it represents the residual capacitance of the leads, terminals, etc., where the shielding is not quite perfect. In calculating the capacitance of the condenser from the above equation, this "leads" reading is subtracted from the value observed when the condenser is in circuit.

By a choice of suitable values for $P$ and $R$, any capacitance in the range $10 \mu f$ to $0.01 \mu f$, or even less, can be measured with accuracy on this bridge. Measurements on each condenser are usually made with two different sets of resistances, so as to get a check on each result, and the two values usually differ by less than 1 part in 10,000. Additional checks are obtained by measuring several condensers separately and then in parallel. The results given below provide examples of such measurements.

The values of $P$ and $R$ used for the majority of the measurements were:

\begin{tabular}{|c|c|c|c|}
\hline$C$ & $P$ & $R$ & $M$ \\
\hline $\begin{array}{l}\mu f \\
1.0\end{array}$ & $\begin{array}{r}\text { Ohms } \\
200 \\
100\end{array}$ & $\begin{array}{r}\text { Ohms } \\
50 \\
100\end{array}$ & $\begin{array}{r}m H \\
10 \\
10\end{array}$ \\
\hline .5 & $\begin{array}{l}200 \\
200\end{array}$ & $\begin{array}{r}100 \\
50\end{array}$ & $\begin{array}{r}10 \\
5\end{array}$ \\
\hline .2 & $\begin{array}{l}500 \\
200\end{array}$ & $\begin{array}{l}100 \\
100\end{array}$ & $\begin{array}{r}10 \\
4\end{array}$ \\
\hline .1 & $\begin{array}{l}500 \\
500\end{array}$ & $\begin{array}{l}200 \\
100\end{array}$ & $\begin{array}{r}10 \\
5\end{array}$ \\
\hline .05 & $\begin{array}{r}1,000 \\
500\end{array}$ & $\begin{array}{l}200 \\
200\end{array}$ & $\begin{array}{r}10 \\
5\end{array}$ \\
\hline .02 & $\begin{array}{l}1,000 \\
1,000\end{array}$ & $\begin{array}{l}500 \\
200\end{array}$ & $\begin{array}{r}10 \\
4\end{array}$ \\
\hline .01 & $\begin{array}{l}2,000 \\
1,000\end{array}$ & $\begin{array}{l}500 \\
500\end{array}$ & $\begin{array}{r}10 \\
5\end{array}$ \\
\hline
\end{tabular}

Note.-The value of $S$ is, of course, determined by the values of $R, L$, and $M$.

\section{RESULTS}

The results are embodied in Tables 1 to 6 , inclusive. They naturally divide into two parts, namely, those on capacitance (Tables 1 to 4 ) and those on power factor (Tables 5 and 6 ).

In Table 1 are given the values of the capacitances as determined in 1928 at the two laboratories. The results indicate, as was shown by later measurements, that the capacitor during transportation from the United States to England on its first transit had been subjected to conditions that caused a decrease in the capacitance of each 
of the sections. This rendered the intercomparison of little value. However, the differences as shown in Table 2 suggest that the measured value of the change of capacitance with frequency in the two laboratories was not the same by 1 or 2 parts in 10,000 .

TABLE 1.-Capacitance at four frequencies as measured in 1928

[Capacitance in International Microfarads at $25.0 \pm 1_{1}^{\circ} \mathrm{C}$.]

\begin{tabular}{|c|c|c|c|c|c|c|c|c|}
\hline \multirow{2}{*}{$\begin{array}{l}\text { Con- } \\
\text { denser } \\
\text { section }\end{array}$} & \multicolumn{4}{|c|}{ Burean of Standards, May, 1928} & \multicolumn{4}{|c|}{$\begin{array}{c}\text { National Physical Laboratory, Novem- } \\
\text { ber, } 1928\end{array}$} \\
\hline & $60 \sim$ & $100 \sim$ & $1000 \sim$ & $2000 \sim$ & $60 \sim$ & $100 \sim$ & $1000 \sim$ & $2000 \sim$ \\
\hline $\begin{array}{l}0.01 \\
.02 \\
.02^{\prime} \\
.05 \\
.1\end{array}$ & $\begin{array}{c}0.010074 \\
.020080 \\
.020146 \\
.050076 \\
.10027\end{array}$ & $\begin{array}{l}0.010073 \\
.020071 \\
.020137 \\
.050059 \\
.10024\end{array}$ & $\begin{array}{l}0.010058 \\
.020061 \\
.020118 \\
.050019 \\
.10013\end{array}$ & $\begin{array}{c}0.010059 \\
.020059 \\
.020113 \\
.050013 \\
.10009\end{array}$ & $\begin{array}{c}0.010061 \\
.020062 \\
.020127 \\
.050049 \\
.10024\end{array}$ & $\begin{array}{l}0.010055 \\
.020052 \\
.020118 \\
.05003_{0} \\
.10021\end{array}$ & $\begin{array}{l}0.010037 \\
.020040 \\
.020097 \\
.049983 \\
.10008\end{array}$ & $\begin{array}{c}0.010033 \\
.020036 \\
.020090 \\
.049955 \\
.10003\end{array}$ \\
\hline $\begin{array}{r}.1^{\prime} \\
.2 \\
.5 \\
21.0\end{array}$ & $\begin{array}{l}.10041 \\
.20005 \\
.50104 \\
1.0023\end{array}$ & $\begin{array}{l}.10037 \\
.20002 \\
.50103 \\
1.0022\end{array}$ & $\begin{array}{l}.10028 \\
.19991 \\
.50083 \\
1.0014\end{array}$ & $\begin{array}{r}.10024 \\
.19983 \\
.50050 \\
1.0012\end{array}$ & $\begin{array}{r}.10038 \\
.19997 \\
.5008_{6} \\
1.0017\end{array}$ & $\begin{array}{r}.10035 \\
.19993 \\
.50078 \\
1.0016\end{array}$ & $\begin{array}{r}.10023 \\
.19980 \\
.5005_{1} \\
1.0008\end{array}$ & $\begin{array}{l}.10019 \\
.19972 \\
.50035 \\
1.0002\end{array}$ \\
\hline
\end{tabular}

TABLE 2.-Differences in capacitance in parts in 10,000 between the Bureau of Standards results of May, 1928, and the National Physical Laboratory results of November, 1928

[In all cases the Bureau of Standards results were larger]

\begin{tabular}{|c|c|c|c|c|}
\hline $\begin{array}{l}\text { Condenser } \\
\text { section }\end{array}$ & $60 \sim$ & $100 \sim$ & $1,000 \sim$ & 2,000 . \\
\hline $\begin{array}{c}0.01 \\
.02 \\
.02^{\prime} \\
.05 \\
.1\end{array}$ & $\begin{array}{r}13 \\
9 \\
10 \\
5 \\
3\end{array}$ & $\begin{array}{r}18 \\
10 \\
9 \\
6 \\
3\end{array}$ & $\begin{array}{r}21 \\
11 \\
11 \\
7 \\
5\end{array}$ & $\begin{array}{r}26 \\
12 \\
12 \\
10 \\
6\end{array}$ \\
\hline $\begin{array}{r}.1^{\prime} \\
.2 \\
.5 \\
\therefore 1.0\end{array}$ & $\begin{array}{l}3 \\
4 \\
4 \\
6\end{array}$ & $\begin{array}{l}2 \\
5 \\
5 \\
6\end{array}$ & $\begin{array}{l}5 \\
6 \\
6 \\
6\end{array}$ & $\begin{array}{r}5 \\
6 \\
3 \\
10\end{array}$ \\
\hline
\end{tabular}

A possible discrepancy of this order in the methods of measurement was considered to merit special attention, since the determination of this quantity is based on entirely different assumptions at the two laboratories. At the Bureau of Standards the capacitance of the air capacitor is assumed to be invariable with frequency. At the National Physical Laboratory the changes in the value of the standard mutual inductors are deduced from observations of self-capacitance made at radio-frequencies on specially constructed coils. In the subsequent measurements there was no consistent difference between the measured values of the change of capacitance with frequency, and it is concluded that both systems of measurement give the same result within the limits of error of this investigation.

The results, on individual sections, of all capacitance measurements subsequent to the first set made at the Bureau of Standards are given in Table 3 . The values show a remarkably good agreement in the measurements at the two laboratories. When the work was begun the lack of stability of the capacitor (the best at that time available) was appreciated, and no effort made to obtain values 
with an accuracy greater than 1 or 2 parts in 10,000. Hence, while the instability of the capacitor may explain the recorded differences, yet the possibility of an experimental error in the last recorded figure exists in every case. It appears certain that the microfarad and its subdivisions have the same value at the two laboratories as accurately as can be determined by transporting the present mica capacitor; that is, within 1 or 2 parts in 10,000. Since very different methods are used at the two laboratories for establishing the unit of capacitance from the units of resistance and time, this agreement shows that both methods give precise results. A more accurate comparison must await the construction of more stable standards.

TABLE 3.-Values of capacitance of the individual sections of subdivided capacitor B. S. 16390 as determined at the National Physical Laboratory and the Bureau of Standards between January, 1929, and March, 1931, inclusive

[Capacitance in microfarads]

N. P. L., January, 1929
B. S., June, 1929
B. S., January, 1930 P. L., September, 1930 .
B. S., March, 1931
B. S., February, 1932

N. P. L., January, 1929

B. S., June, 1929

B. S., January, 1930

N. P. L., September, 1930

B. S., March, 1931 .

B. S., February, 1932

\begin{tabular}{|c|c|c|c|}
\hline \multicolumn{2}{|c|}{0.01 section } & \multicolumn{2}{|c|}{0.02 section } \\
\hline $60 \sim$ & $1,000 \sim$ & $60 \sim$ & $1,000 \sim$ \\
\hline $\begin{array}{r}0.010061 \\
.010063 \\
.010067 \\
.010061 \\
.010070 \\
.010066\end{array}$ & $\begin{array}{r}0.010037 \\
.010042 \\
.010045 \\
.010041 \\
.010047 \\
.010045\end{array}$ & $\begin{array}{r}0.020062 \\
.020059 \\
.020060 \\
.020062 \\
.020070 \\
.020059\end{array}$ & $\begin{array}{r}0.020040 \\
.020043 \\
.020048 \\
.020043 \\
.020056 \\
.020046\end{array}$ \\
\hline \multicolumn{2}{|c|}{$0.02^{\prime}$ section } & \multicolumn{2}{|c|}{0.05 section } \\
\hline $60 \sim$ & $1,000 \sim$ & $60 \sim$ & $1,000 \sim$ \\
\hline $\begin{array}{r}0.020127 \\
.020125 \\
.020129 \\
.020127 \\
.020134 \\
.020127\end{array}$ & $\begin{array}{r}0.020097 \\
.020101 \\
.020106 \\
.020099 \\
.020111 \\
.020104\end{array}$ & $\begin{array}{r}0.050049 \\
.050051 \\
.050057 \\
.050053 \\
.050059 \\
.050071\end{array}$ & $\begin{array}{r}0.049983 \\
.049993 \\
.050002 \\
.050000 \\
.050007 \\
.050012\end{array}$ \\
\hline \multicolumn{2}{|c|}{0.1 section } & \multicolumn{2}{|c|}{$0.1^{\prime}$ section } \\
\hline $60 \sim$ & $1,000 \sim$ & $60 \sim$ & $1,000 \sim$ \\
\hline $\begin{array}{r}0.10024 \\
.10024 \\
.10024 \\
.10023 \\
.10022 \\
.10025\end{array}$ & $\begin{array}{r}0.10008 \\
.10009 \\
.10008 \\
.10009 \\
.10010 \\
.10011\end{array}$ & $\begin{array}{r}0.10038 \\
.10038 \\
.10038 \\
.10038 \\
.10036 \\
.10038\end{array}$ & $\begin{array}{r}0.10023 \\
.10024 \\
.10023 \\
.10025 \\
.10025 \\
.10025\end{array}$ \\
\hline \multicolumn{2}{|c|}{0.2 section } & \multicolumn{2}{|c|}{0.5 section } \\
\hline $60 \sim$ & $1,000 \sim$ & $60 \sim$ & $1,000 \sim$ \\
\hline $\begin{array}{r}0.19997 \\
.19999 \\
.19999 \\
.19998 \\
.19996 \\
.20000\end{array}$ & $\begin{array}{r}0.19980 \\
.19983 \\
.19983 \\
.19984 \\
.19985 \\
.19981\end{array}$ & $\begin{array}{r}0.50086 \\
.50095 \\
.50091 \\
.50083 \\
.50081 \\
.50093\end{array}$ & $\begin{array}{r}0.50051 \\
.50060 \\
.50061 \\
.50050 \\
.50063 \\
.50070\end{array}$ \\
\hline
\end{tabular}

N. P. L., January, 1929

B. S., June, 1929

B. S., January, 1930

N. P. L., September, 1930

B. S., March, 1931

B. S., February, 1932 
The values obtained on the $\Sigma$ sections are given in Table 4 . The measured values were obtained by actual measurements on sections connected in parallel; the computed values are the sum of the measured values of the same sections as measured individually. The values are in exceptionally good agreement, the recorded differences being well within the limits of error of the measurements. The greatest difference is in the Bureau of Standards values of the $\Sigma 0.05$ section for March, 1931, where the measured and computed values differ by 4 parts in 10,000 .

TABLE 4.-Measured and computed values of capacitance of the $\Sigma$ sections of subdivided capacitor B. S. 16390 as determined at the National Physical Laboratory and the Bureau of Standards between January, 1929, and March, 1931, inclusive

[Capacitance in microfarads]

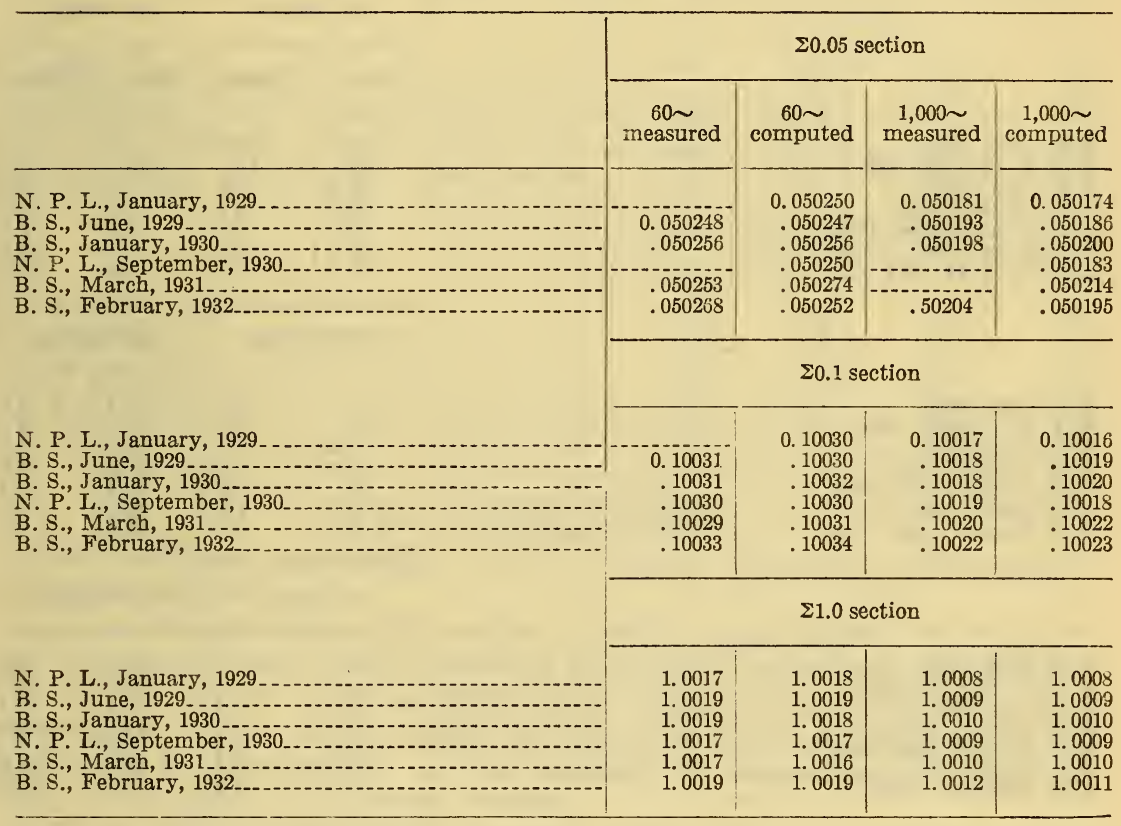

The values of the power factor of the individual sections as obtained at 60 and 1,000 cycles are given in Table 5 . As the power factor values are not affected by the capacitance changes which occurred during the first transit, the results of the first Bureau of Standards determination are inlcuded in the table. The values are in most cases given to the fifth decimal place (example: $16.1 \times 10^{-4}=0.00161$ ), since, for some sections, the differences between the two laboratories can only be made apparent by recording the fifth place. Variations in the fourth place are to be expected when the capacitance measurements are made with an accuracy of 1 in 10,000 . There is no systematic difference between the values as obtained in the two laboratories. For all sections the agreement at 60 cycles is somewhat better than at 1,000 cycles. The differences in the tabulated values are probably the result of experimental errors.

The results of the measured and computed values of the power factor on the $\Sigma$ sections are given in Table 6 . The measured values 
were obtained by a measurement on sections connected in parallel. The computed values were determined as the mean, weighted according to the value of the capacitance, of the measured values of the individual sections. The results are in substantial agreement for a given section at a given frequency. As with the individual section, the 60 -cycle values show smaller differences than the 1,000-cycle values. The results for a given section can be depended upon to about one in the fourth decimal place.

TABLE 5.-Values of power factor of the individual sections of subdivided capacitor B. S. 16390 as determined at the National Physical Laboratory and the Bureau of Standards between January, 1929, and March, 1981, inclusive

[Values must be multiplied by 10-4]

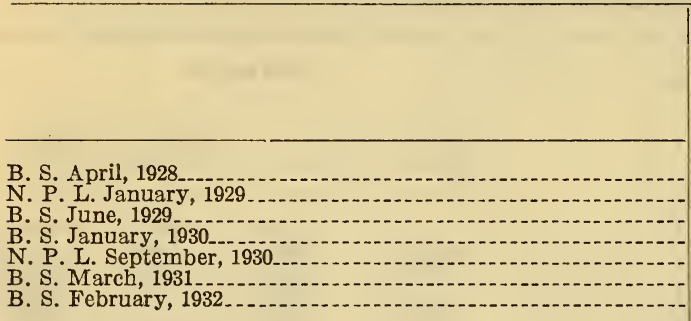

B. S. April, 1928

N. P. L. January, 1929

B. S. June, 1929

B. S. January, 1930

N. P. L. September, 1930

B. S. March, 1931

B. S. February, 1932

B. S. April, 1928

N. P. L. January, 1929

B. S. June, 1929

B. S. January, 1930

N. P. L September, 1930

B. S. March, 1931

\begin{tabular}{|c|c|c|c|}
\hline \multicolumn{2}{|c|}{0.01 section } & \multicolumn{2}{|c|}{0.02 section } \\
\hline $60 \sim$ & $1,000 \sim$ & $60 \sim$ & $1,000 \sim$ \\
\hline $\begin{array}{l}16.1 \\
15 . \\
14.0 \\
14.0 \\
14 . \\
14.9 \\
14.8\end{array}$ & $\begin{array}{r}11.0 \\
11 . \\
6.8 \\
8.7 \\
9.2 \\
7.0 \\
10.3\end{array}$ & $\begin{array}{l}8.2 \\
6 . \\
7.4 \\
7.3 \\
7.5 \\
7.4 \\
7.8\end{array}$ & $\begin{array}{l}3.2 \\
3.7 \\
2.2 \\
2.8 \\
2.5 \\
2.5 \\
2.7\end{array}$ \\
\hline \multicolumn{2}{|c|}{$0.02^{\prime}$ section } & \multicolumn{2}{|c|}{0.05 section } \\
\hline $\begin{array}{l}9.7 \\
8 . \\
8.9 \\
8.9 \\
8 . \\
9.5 \\
9.4\end{array}$ & $\begin{array}{l}6.3 \\
6.6 \\
4.8 \\
6.0 \\
5.0 \\
4.9 \\
5.6\end{array}$ & $\begin{array}{l}12.6 \\
11 . \\
11.2 \\
11.2 \\
11.2 \\
10.1 \\
11.3\end{array}$ & $\begin{array}{l}5.6 \\
4.7 \\
3.9 \\
4.0 \\
4.4 \\
3.0 \\
4.8\end{array}$ \\
\hline \multicolumn{2}{|c|}{0.1 section } & \multicolumn{2}{|c|}{$0.1^{\prime}$ section } \\
\hline $\begin{array}{l}10.7 \\
11.1 \\
11.1 \\
10.8 \\
11.7 \\
10.3 \\
10.8\end{array}$ & $\begin{array}{l}6.8 \\
6.9 \\
6.1 \\
6.4 \\
6.4 \\
5.5 \\
6.6\end{array}$ & $\begin{array}{l}10.9 \\
11.3 \\
11.4 \\
11.1 \\
12.1 \\
10.2 \\
11.0\end{array}$ & $\begin{array}{l}6.0 \\
5.9 \\
5.1 \\
5.3 \\
5.1 \\
4.6 \\
5.9\end{array}$ \\
\hline \multicolumn{2}{|c|}{0.2 section } & \multicolumn{2}{|c|}{0.5 section } \\
\hline $\begin{array}{l}5.8 \\
5.8 \\
5.7 \\
5.5 \\
5.8 \\
5.1 \\
5.7\end{array}$ & $\begin{array}{l}4.6 \\
3.8 \\
3.9 \\
3.4 \\
3.4 \\
2.2 \\
3.2\end{array}$ & $\begin{array}{l}5.7 \\
5.5 \\
5.5 \\
5.1 \\
6.3 \\
4.9 \\
5.4\end{array}$ & $\begin{array}{l}4.1 \\
3.0 \\
3.4 \\
3.4 \\
2.5 \\
2.2 \\
2.5\end{array}$ \\
\hline
\end{tabular}

In addition to the data on power factor given in the tables, the power factor was determined at 100 and 2,000 cycles at the time of the first measurement in each laboratory. The agreement was about the same as for 60 and 1,000 cycles, so that tables giving these values do not appear. 
TABLE 6.-Measured and computed values of power factor of the $\Sigma$ sections of subdivided capacitor B. S. 16390 as determined at the National Physical Laboratory and the Bureau of Standards between January, 1929, and March, 1931, inclusive

[Values must be inultiplied by $10^{-4}$ ]

\begin{tabular}{|c|c|c|c|c|}
\hline & \multicolumn{4}{|c|}{$\Sigma 0.05$ section } \\
\hline & $\begin{array}{c}60 \sim \\
\text { measured }\end{array}$ & $\begin{array}{l}60 \sim \\
\text { computed }\end{array}$ & $\begin{array}{l}1,000 \sim \\
\text { measured }\end{array}$ & $\begin{array}{c}1,000 \sim \\
\text { computed }\end{array}$ \\
\hline \multirow{5}{*}{$\begin{array}{l}\text { B. S. April, 1928 } \\
\text { N. P. L. January, } 1929 \\
\text { B. S. June, } 1929 \\
\text { B. S. January, } 1930 \text { N. P. L. September, } 1930 \\
\text { B. S. Mareh, } 1931 \\
\text { B. S. February, } 1932\end{array}$} & 10.3 & \multirow{4}{*}{$\begin{array}{r}10.4 \\
8.6 \\
11.1 \\
9.4 \\
9.0 \\
9.0 \\
10.3\end{array}$} & & \multirow{4}{*}{$\begin{array}{l}5.8 \\
6.2 \\
4.1 \\
5.3 \\
4.8 \\
4.4 \\
5.4\end{array}$} \\
\hline & 9.9 & & 5.1 & \\
\hline & $\begin{array}{r}9.7 \\
-. . .\end{array}$ & & $\begin{array}{c}5.1 \\
-\cdots\end{array}$ & \\
\hline & $\begin{array}{r}9.3 \\
9.7\end{array}$ & & & \\
\hline & \multicolumn{4}{|c|}{$\Sigma 0.1$ section } \\
\hline \multirow{5}{*}{$\begin{array}{l}\text { B. S. April, 1928 } \\
\text { N. P. L. January, } 19299 \\
\text { B. S. June, } 1929 \\
\text { B. S. January, } 1930 \\
\text { N. P. L. September, } 1930 \\
\text { B. S. March, } 1931 . \\
\text { B. S. March, } 1932\end{array}$} & 11.1 & \multirow{5}{*}{$\begin{array}{r}11.6 \\
9.8 \\
10.5 \\
10.3 \\
10.1 \\
9.7 \\
10.5\end{array}$} & \multirow{5}{*}{$\begin{array}{l}\text { 5. } 6 \\
5.5 \\
4.5 \\
5.1 \\
4.7 \\
4.2 \\
4.9\end{array}$} & \multirow{5}{*}{$\begin{array}{l}5.8 \\
5.3 \\
4.5 \\
5.0 \\
4.6 \\
3.7 \\
5.1\end{array}$} \\
\hline & 10.5 & & & \\
\hline & 10.3 & & & \\
\hline & 10.5 & & & \\
\hline & 10.1 & & & \\
\hline & \multicolumn{4}{|c|}{$\Sigma 1.0$ section } \\
\hline 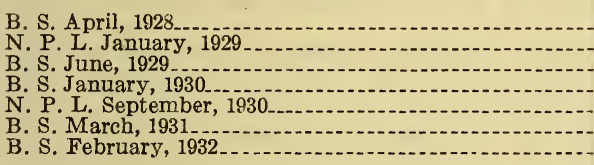 & $\begin{array}{l}7.2 \\
6.8 \\
7.0 \\
6.5 \\
7.5 \\
6.6 \\
7.3\end{array}$ & $\begin{array}{l}7.7 \\
7.1 \\
7.2 \\
6.8 \\
7.7 \\
6.5 \\
7.0\end{array}$ & $\begin{array}{l}5.8 \\
3.5 \\
4.4 \\
5.3 \\
3.3 \\
4.0 \\
4.4\end{array}$ & $\begin{array}{l}4.9 \\
4.1 \\
4.0 \\
4.1 \\
3.5 \\
3.0 \\
4.6\end{array}$ \\
\hline
\end{tabular}

\section{CONCLUSIONS}

The following conclusions can be drawn from the information herein presented:

1. The transportation of a mica capacitor may cause a change in the capacitance even when there is no visible indication of damage.

2. So far as the measurements here reported are concerned, the capacitance of an air capacitor of the type used at the Bureau of Standards is independent of the method of measurenent, at least with an accuracy of 1 part in 10,000.

3. The mutual inductance between the coils of the standard inductor of the National Physical Laboratory can be computed from its dimensions and a correction made for the capacitance between the coils for all frequencies here reported, at least with an accuracy of 1 part in 10,000.

4. The unit of capacitance, the microfarad, is the same in the Bureau of Standards and the National Physical Laboratory within the limits of accuracy of the present measurements, about 1 in 10,000.

5. Measurements at the two laboratories of the power factor at any frequency below 1,000 cycles give values which agree to one or two in the fourth decimal place.

6 . Increased accuracy in intercomparison must await the development of more stable standards of capacitance.

The authors wish to express appreciation of the help received from their associates in the two laboratories.

Washington and Teddington, March 1, 1932. 